\title{
PERILAKU PROKRASTINASI AKADEMIK DAN LAYANAN BIMBINGAN DAN KONSELING
}

\section{BEHAVIOUR OF ACADEMIC PROCRASTINATION AND GUIDANCE AND COUNSELING SERVICES}

\author{
IK Rahman'1a, H Indra' ${ }^{1}$, dan R Kasman² \\ 1 Program Studi Magister Pendidikan Agama Islam, Sekolah Pascasarjana Universitas Ibn Khaldun \\ (UIKA) Bogor, Jl. K.H. Soleh Iskandar Km.2 Kota Bogor 16162 \\ 2 Program Studi Pendidikan Luar Sekolah, Fakultas Keguruan dan Ilmu Pendidikan \\ Universitas Ibn Khaldun (UIKA) Bogor, Jl. K.H. Soleh Iskandar Km.2 Kota Bogor 16162 \\ a Korespondensi: Imas Kania Rahman, Email: imas.kania@uika-bogor.ac.id \\ (Diterima: 15-10-2018; Ditelaah: 15-10-2018; Disetujui: 27-10-2018)
}

\begin{abstract}
This study aimed to describe the forms of student behavior in cases of academic procrastination and the pattern of guidance and counseling services for these students at Islamic University. Field qualitative research was conducted at UIKA Bogor , UIN Bandung and UIN Yogyakarta. Technique of collecting data trough interviews, observations and documents. Primary data source are vice rector, dean, head of study program, Guidance and Counseling lecturer, and students. Secondary data are risult of observation and documents. The results showed that the behaviours of academic procrastination at Islamic University students could be described as follows: late entering class and not being disciplined according to schedule, procrastinating carrying out academic assignments from subject lecturers, avoiding certain tasks, choosing other activities and learning permits in class, the number of attendance did not meet the minimum requirements, the grade was below standard or not passed, IPK was below standard, and threatened Drop Out (DO). The implementation of guidance and counseling services at Islamic University had not run synergistically between the Intruksional Kurikuler (IK), AdministrasiPendidikan (AK) and Guidance and Counseling (BK). Guidance and counseling services had not had specially aim for helping students in cases of academic procrastination, more focused on career services (career center). The lack of support from the leadership, professional human resources was not available, and there was no regulation governing the comprehensive guidance and counseling services at Islamic University.
\end{abstract}

Keywords: academic procrastination, guidance and counselings.

\begin{abstract}
ABSTRAK
Penelitian ini bertujuan mendeskripsikan tentang bentuk-bentuk perilaku mahasiswa kasus prokrastinasi akademik dan pola pelayanan bimbingan dan konseling bagi mahasiswa tersebut di PTAI. Penelitian kualitatif lapangan (field research) dilaksanakan di Universitas Ibnu Khaldun (UIKA) Bogor, UIN Sunan Gunung Djati Bandung dan UIN Sunan Kalijaga Yogyakarta. Teknik pengambilan data melalui wawancara, pengamatan dan dokumen. Sumber data primer adalah wakil rektor, pimpinan fakultas, pimpinan program studi, dosen Bimbingan dan Konseling dan mahasiswa. Data sekunder diperoleh melalui pengamatan dan dokumen. Hasil penelitian menunjukan bahwa perilaku prokrastinasi akademik yang paling sering ditemukan di lingkungan mahasiswa PTAI dapat dideskripsikan sebagai berikut: terlambat masuk kelas dan tidak disiplin sesuai jadwal, menunda-nunda melaksanakan tugas akademik dari dosen pengampu mata kuliah, menghindari tugas tertentu, memilih
\end{abstract}


melakukan aktivitas lain dan izin belajar di kelas, jumlah kehadiran tidak memenuhi syarat minimal, nilai mata kuliah di bawah standar atau tidak lulus, IPK di bawah standar, dan terancam DO. Penyelenggaraan pelayanan bimbingan dan konseling di PTAI belum memiliki pola yang utuh sesuai standar, yang berjalan secara sinergis antara Intruksional Kurikuler (IK), Administrasi Kependidikan (AK) dan Bimbingan dan Konseling (BK). Pelayanan bimbingan dan konseling belum memiliki pola dan pendekatan yang bertujuan khusus untuk membantu mahasiswa kasus prokrastinasi akademik. Wadah layanan bimbingan dan konseling lebih fokus pada pelayanan bidang karir (career center). Minimnya dukungan dari pimpinan, SDM profesional tidak tersedia, dan belum ada regulasi yang mengatur pelayanan BK komprehensif yang merupakan faktor tidak berkembanganya layanan bimbingan dan konseling di Perguruan Tinggi Agama Islam (PTAI).

Kata kunci: pelayanan bimbingan dan konseling, prokrastinasi akademik.

Rahman, I. K., Indra, H., \& Kasman, R. (2018). Perilaku Prokrastinasi Akademik dan Layanan Bimbingan dan Konseling. Tadbir Muwahhid, 2(2), 111-119.

\section{PENDAHULUAN}

Penelitian tentang fenomena mahasiswa prokrastinasi akademik yang dilakukan di Sekolah Tinggi Agama Islam Sufyan Tsauri di Majenang, Jawa Tengah menunjukan hasil yang memprihantinkan. Hal tersebut dapat dijadikan potret keadaan mahasiswa di semua perguruan tinggi di Indonesia. Peneliti melakukan eksperimen dalam upaya untuk membantu mahasiswa kasus prokrastinasi akademik dengan menggunakan pendekatan Solution Focused Brief Therapy (SFBT) berbasis Islam. Hasil penelitian menunjukan bahwa pendekatan tersebut efektif untuk meningkatkan regulasi diri mahasiswa kasus prokrastinasi akademik.

Regulasi yang diterbitkan oleh Kemenristekdikti No.44 Tahun 2015 tentang Standar Nasional Pendidikan Tinggi (SN Dikti) mengatur tentang pemberlakukan Sistem Kredit Semester (SKS), lama studi, kualitas pembimbing dan promotor, jumlah maksimal mahasiswa yang dibimbing, dan standar publikasi ilmiah yang diberlakukan sama untuk semua perguruan tinggi di Indonesia. Regulasi ini menyadarkan banyak pihak bahwa tidak sedikit mahasiswa yang drop out diakibatkan oleh kasus prokrastinasi akademik. Penyebab mahasiswa yang terkena drop out bukan karena kemampuan berpikir yang lemah atau dinilai sebagai mahasiswa tidak potensial, tetapi lebih disebabkan masalah prokrastinasi akademik yang tidak ditangani dengan baik sehingga mahasiswa tidak tertolong dan pada akhirnya masuk ke dalam kategori mahasiswa drop out (DO).

Penelitian di Universitas Muhammadiyah Surakarta tahun 2016 diperoleh data jumlah mahasiswa yang sudah mengambil skripsi sebanyak 4.937 dari jumlah 24.493 mahasiswa aktif tingkat S1 (semua fakultas). Banyak mahasiswa yang tidak mampu menuntaskan skripsinya tepat waktu dan pada akhirnya tidak mampu menuntaskan studinya tepat waktu dan akhirnya mahasiswa tersebut terkena sanksi drop out (DO).

Prokrastinasi berasal dari Bahasa Latin yaitu procrastination. Pro bergerak maju dan crastinus berarti keputusan hari esok. Apabila digabungkan, maka akan bermakna menunda sampai hari esok (Ilyas \& Suryadi, 2015). Prokrastinasi lebih mudah dimaknai dengan perilaku menunda-nunda. 
Prokrastinasi dapat dilakukan dan terjadi pada sebagian hal atau dilakukan pada berbagai hal. Prokastinasi akademik adalah prokastinasi yang sifatnya situasional yang hanya berkorelasi dengan tugas akademik. Prokrastinasi akademik dapat didefiniskan sebagai: 1) kecenderungan atau selalu menunda tugas kuliah, 2) kecenderungan atau selalu mengalami kebimbangan menghadapi tugas kuliah (Basri, 2017).

Vargas (2017) menyatakan bahwa terdapat empat aspek dalam prokrastinasi akademik yaitu: Melibatkan unsur penundaan, baik untuk memulai tugas terkait akademik maupun menyelesaikannya; Berakibat pada perilaku buruk lain yang lebih memprihatinkan; Berimplikasi pada situasi emosional yang tidak nyaman dan tidak menyenangkan seperti rasa cemas, rasa bersalah, marah, dan panik.

Sejalan dengan hasil penelitian Fauziah (2017), perilaku prokrastinasi akademik mahasiswa berhubungan dengan perilaku individu yang cemas takut tidak berhasil dalam membuat makalah (tidak bagus) atau gagal dalam mempresentasikannya di kelas, tidak menyukai tugas yang diberikan oleh dosen, tidak mampu mengontrol dirinya terutama bertahan untuk menuntaskan tugas dari dosen, bahkan cenderung menentang aturan dari dosen, selalu bergantung (dependen) kepada teman satu kelompok dalam mengerjakan dan mempresentasikan tugas, dan sulit dalam mengambil sebuah keputusan.

Menurut Safaati, Halim, dan Iliyati (2017), membagi makna prokrastinasi menjadi tiga kategori, yaitu prokrastinasi: (1) sebagai perilaku penundaan, (2) sebagai suatu kebiasaan yang mengarah kepada trait, (3) sebagai suatu trait kepribadian. Prokrastinasi sebagai prilaku penundaan merupakan perilaku mahasiswa yang cenderung menunda-nunda untuk menyelesaikan tugas paper, tugas power point, laporan observasi, dll tanpa disertai dengan alasan yang jelas.

Sementara itu, prokrastinasi sebagai suatu trait yakni perilaku prokrastinasi yang dipengaruhi dan melibatkan komponen-komponen lain dalam struktur mental yang saling berkaitan. Penelitian yang dilakukan Sujarwo (2015) terhadap mahasiswa semester 4 dan 6 Program Studi Bimbingan dan Konseling Universitas PGRI Palembang menunjukan hasil adanya hubungan yang erat dan signifikan antara regulasi diri dengan prokrastinasi akademik. Begitu pula halnya dengan hasil penelitian Djamarah (2002), yang menunjukan hasil bahwa mahasiswa kasus prokrastinasi adalah mahasiswa dengan regulasi dirinya rendah dan tidak memiliki kemampuan mengatur waktu dengan baik.

Khan, Arif, Noor, dan Muneer (2014) juga berpandangan sama bahwa bentuk prilaku prokrastinasi akademik mahasiswa adalah tidak lulus tepat waktu, menunda tugas membuat paper, tidak siap menghadapi ujian-ujian akademik yang diselenggarakan (UTS dan UAS), malas membaca literatur yang disarankan oleh dosen pengampu mata kuliah, terlambat dalam tugas-tugas administratif seperti mengurus KRS atau mengurus KHS, dalam pembelajaran rutin karena sering bolos, dan kinerja akademik dilakukan beberapa saat menjelang deadline, mengabaikan aktivitas akademik seperti menghadiri seminar ilmiah dan lebih memilih aktivitas yang menyenangkan dan tidak bermanfaat.

Fenomena prokrastinasi akademik terjadi di semua perguruan tinggi dan di semua tingkatan (S1, S2, dan S3). Demikian pula terjadi pada mahasiswa di Universitas Ibn Khaldun (UIKA) Bogor. Dari hasil penelitian diperoleh data bahwa jumlah 
mahasiswa aktif tahun ajaran 2016/2017 sebanyak 5.149 mahasiswa. Apabila mengacu pada regulasi Permenristek Dikti di atas sejatinya mahasiswa angkatan tahun 2012/2013 adalah mahasiswa yang seharusnya siap dan sudah menuntaskan studi. Namun jumlah wisudawan tahun 2016/2017 hanya 835 mahasiswa (dari berbagai tahun angkatan masuk). Hal ini mengidentifikasan bahwa tingginya jumlah mahasiswa yang terindikasi prokrastinasi akademik dan memprihatinkan. Hal ini juga menunjukan bahwa jumlah sumber daya manusia Indonesia usia produktif telah gagal menuntaskan studi di jenjang perguruan tinggi karena prokrastinasi akademik yang tidak terselesaikan.

Faktor penyebab kasus prokrastinasi akademik mahasiswa di antaranya kecanduan game, video porno, pergaulan bebas, kecanduan NAFZA. Hasil penelitian tentang penggunaan gadget menunjukan hasil bahwa durasi penggunaan gadget di lingkungan perguruan tinggi sudah begitu memprihatinkan dan cenderung tidak bisa dikontrol. Penggunaan gadget secara rutin dan dalam durasi waktu yang relatif lama berakibat terhadap perkembangan motorik mereka. Aplikasi yang sering memerangkap mahasiswa dalam jeratan gadget adalah games dan video porno. Kecanduan menonton video porno dan bermain game online berakibat kemunduran akademik pada mahasiswa tersebut (prokrastinasi akademik).

Layanan bimbingan dan konseling merupakan layanan yang dilakukan oleh konselor secara terprogram, sistematis, dan kontinyu dengan tujuan menjembatani dan memfasilitasi perkembangan konseli dalam mencapai tingkat kematangan dan kemandirian. Kematangan bermakna bahwa setiap konseli sampai kepada tugas-tugas perkembangan sesuai

fase perkembangannya. Kemandirian dapat dilihat upaya individu dalam mencapai kebahagian dan kesejahteraan hidup yang selearas dengan nilai-nilai yang dianutnya selalu didasarkan dengan kemampuan pemahaman, penerimaan dirinya dan selalu bertanggung jawab atas keputusan yang diambil.

Tujuan pelayanan bimbingan dan konseling yang diselenggarakan di Indonesia telah dirumuskan oleh pemerintah dalam dua katageri tujuan yaitu tujuan umum dan tujuan khusus. Secar terperinnci tujuan-tujuan tersebut termaktub dalam Permendikbud No.111 Tahun 2014.

Layanan bimbingan dan konseling yang diselenggarakan di Universitas Ibn Khaldun (UIKA) Bogor telah mengarah kepada layanan bimbingan dan konseling komprehensif, terutama di dua fakultas dari tujuh fakultas yang ada. Kedua fakultas tersebut adalah Fakultas Keguruan yaitu FKIP dan FAI yang menanungi Program Studi Pendidikan Agama Islam (PAI) dan Program Guru Madrasah Ibtidaiyah (PGMI). Terbentuknya Unit Layanan BK pada kedua fakultas tersebut sejatinya atas kesadaran buttom-up dengan kata lain merupakan kesadaran dari fakultas tentang pentingnya untuk menyelenggarakan layanan bimbingan dan konseling.

Dalam upaya pengembangan dan peningkatkan bantuan layanan bimbingan dan konseling di perguruan tinggi perlu diperhatikan tigal hal yaitu komitmen institusi, pertimbangan perencanaan, dan pelayananan yang komprehensif. Hal itu dapat dilakukan dengan pendekatan preventif, kuratif, dan pengembangan (Wahyuni, Nurihsan, \& Yusuf, 2018).

Amti dan Prayitno (1999) menjelaskan bahwa Unit Pelaksana Bimbingan dan Konseling (UPBK) selain bertugas melayani 
bidang karir juga penting melayani bidang pribadi, sosial, dan akademik terhadap individu atau sekelompok individu.

Layanan bimbingan dan konseling di perguruan tinggi berperan penting dalam membantu mahasiswa kasus prokrastinasi akademik. Dibutuhkan pendekatan bimbingan dan konseling komprehensif yang efektif dan efisien. Target penelitian ini adalah untuk memperoleh deskripsi atau gambaran yang lebih jelas tentang bentukbentuk perilaku prokrastinasi akademik mahasiswa dan layanan bimbingan dan konseling yang sudah diupayakan dan dilakukan oleh Perguruan Tinggi Agama Islam (PTAI) saat ini, agar dapat dilakukan evaluasi dan pengembangan terhadap layanan bimbingan dan konseling tersebut.

\section{MATERI DAN METODE}

Penelitian ini menggunakan pendekatan kualitatif dengan metode field research, yaitu pengumpulan data yang dilakukan dengan penelitian di tempat terjadinya gejala-gejala yang diselidiki (Hadi, 2009). Penelitian dilakukan di lingkungan Perguruan Tinggi Agama Islam pada tiga universitas yaitu Universitas Ibn Khaldun (UIKA) Bogor, UIN Sunan Gunung Djati Bandung, dan UIN Sunan Kalijaga Yogyakarta.

Teknik pengumpulan data dilakukan dengan wawancara, dokumen dan observasi. Wawancara digunakan untuk menggali data tentang bentuk perilaku prokrastinasi akademik mahasiswa dan layanan BK dari sumber data primer, yaitu wakil rektor dua PTAI, dekan dua PTAI, kepala program studi tiga PTAI, dosen pengampu mata kuliah Bimbingan dan
Konseling tiga PTAI, dan mahasiswa pada tiga perguruan tinggi tersebut.

Data yang diperoleh dari dokumen adalah data terkait jumlah mahasiswa, nama-nama mahasiswa, absensi kehadiran mahasiswa, dan nilai indek prestasi kumulatif (IPK). Visi dan misi, program dan dokumen kegiatan yang telah diselenggarakan career center dan layanan BK fakultas. Observasi dilakukan pada tiga PTAI dan beberapa fakultas yang dinaunginya.

Teknik analisis data menggunakan model analisis Miles dan Hubarman dengan tahapan sebagai berikut: reduksi data, pengumpulan data, display data, dan verifikasi. Untuk menguji kebenaran data dilakukan triangulasi data. Moleong (2012), menyatakan trianggulasi data yang dapat digunakan dalam teknik pemeriksaan adalah sumber, metode, penyidik, dan teori. Penelitian ini menggunakan triangulasi sumber dengan cara melakukan perbandingan dan melakukan cross check terhadap derajat kepercayaan informasi atau data yang diperoleh dengan sumber informasi atau data dari sumber yang lain.

\section{HASIL DAN PEMBAHASAN}

Hasil penelitian diperoleh kesimpulan bahwa persentase jumlah mahasiswa prokrastinasi akademik di lingkungan PTAI relatif sama. Sebagai gambaran persentase mahasiswa kasus prokrastinasi akademik Tahun Ajaran 2017/2018 pada salah satu fakultas di Universitas Ibn Khaldun (UIKA) Bogor relatif sama dengan persentase mahasiswa prokrastinasi akademik hasil penelitian lainnya. 
Tabel 1 Persentase mahasiswa prokrastinasi akademik tahun ajaran 2017/2018

\begin{tabular}{llrrrrrrr}
\hline \multirow{2}{*}{ No } & \multirow{2}{*}{$\begin{array}{c}\text { Program } \\
\text { Studi }\end{array}$} & \multirow{2}{*}{$\begin{array}{c}\text { Jumlah } \\
\text { Mahasiswa }\end{array}$} & \multicolumn{2}{c}{ IPK $\leq 2$} & \multicolumn{2}{c}{ Terancam DO } & \multicolumn{2}{c}{$\begin{array}{c}\text { Jumlah Mahasiswa } \\
\text { Prokrastinasi }\end{array}$} \\
\cline { 4 - 10 } & & & Total & \multicolumn{1}{c}{$\%$} & Total & $\%$ & Total & $\%$ \\
\hline 1 & PAI & 473 & 24 & 5,7 & 35 & 7,9 & 59 & 12,5 \\
2 & PGMI & 122 & - & - & 21 & 17,2 & 21 & 17,2 \\
3 & KPI & 87 & 9 & 10,3 & 5 & 5,7 & 14 & 16,1 \\
4 & Esy & 307 & 6 & 2 & 6 & 24,8 & 82 & 26,7 \\
5 & Asy & 58 & 7 & 12,1 & 6 & 10,3 & 13 & 22,4 \\
\hline
\end{tabular}

Tabel 1 mendeskripsikan bahwa jumlah mahasiswa kasus prokrastinasi akademik sebanyak 186 orang dari jumlah total 1.047 mahasiswa atau sebesar 17,76\%. Jumlah mahasiswa kasus prokrastinasi akademik satu fakultas sudah menunjukan jumlah yang memprihatinkan apalagi jika ditambah dengan jumlah mahasiswa kasus prokrastinasi akademik dari berbagai fakultas lingkungan Perguruan Tinggi Agama Islam dan diakumulasi pada seluruh Perguruan Tinggi Agama Islam.

Hasil penelitian Nur Fitriana Anisa Putri di Universitas Negeri Sebelas Maret (UNS) menunjukan prokrastinasi akademik mahasiswa Prodi Psikologi UNS Solo mencapai $13,68 \%$ prokrastinasi katagori tinggi, 74,74\% katagori sedang, dan 11,58\% prokrastinasi katagori rendah. Pengaruh self efficacy terhadap prilaku prokrastinasi akademik mahasiswa sebesar 23,8\%. Sedangkan prokastinasi akademik mahasiswa yang dipengaruhi oleh faktor lain sebesar 76,2\%.

Bentuk perilaku prokrastinasi akademik di lingkungan Perguruan Tinggi Agama Islam relatif sama, baik di tiga perguruan tinggi yang menjadi lapanagn penelitian juga di PTAI lainnya dari hasil penelitian sebelumnya. Ditemukan bahwa lebih banyak jenis prokrastinasi akademik disfungsional. Bentuk-bentuk perilaku prokrastinasi akademik mahasiswa di Perguruan Tingi Agama Islam bermula dari kesulitan yang dialami mahasiswa dalam merencanakan, melaksanakan, dan mengoptimalkan perkembangan belajarnya. Perilaku-perilaku prokrastinasi akademik yang banyak dijumpai adalah: masuk kelas tidak tepat waktu dan tidak disiplin sesuai jadwal yang telah ditetapkan, menundanunda melaksanakan tugas akademik, menghindari tugas tertentu seperti presentasi, mendahulukan kegiatan yang tidak berkaitan dengan tugas dan izin belajar di kelas, jumlah kehadiran tidak susuai aturan minimal, memperoleh nilai tidak lulus, IPK di bawah standar, dan terancam DO karena melewati batas maksimal lama studi.

Rahmat Aziz (2015), hasil penelitiannya di UIN Maulana Malik Ibrahim Malang, menunjukan ada korelasi yang tinggi antara prokrastinasi akademik mahasiswa (S2) dengan konsep diri sebesar 33\%. Bentuk prilaku prokrastinasi akademik di antaranya terbiasa melakukan prilaku tidak menyegerakan untuk menyelesaikan tugas yang diberikan dosen, tidak maksimal dalam melakukan presentasi di kelas, terlambat mengumpulkan makalah, malas untuk melakukan pertemuan dan diskusi dengan dosen pembimbing tesis. Aziz menyampaikan pentingnya strategi menyelesaikan masalah prokrastinasi akademik karena beranggapan bahwa masalah ini akan memberikan akibat buruk terhadap citra perguruan tinggi dalam jangka panjang dan tidak tercapinya tujuan 
pendidikan nasional. Menurut Rahmat (2015), dalam jangka panjang mahasiswa kasus prokrastinasi memiliki kecenderungan menjadi pembohong, dengan berbagai alasan yang dicari-cari.

Wolters (2003) menegaskan bahwa mengabaikan perilaku prokrastinasi akademik berarti membiarkan prokrastinator menuju kepada perilaku curang dalam memenuhi tugas akademiknya seperti plagiarisme, jasa pembuatan skripsi, dan jual beli gelar akademik. Jelas bahwa prokrastinasi akademik urgen untuk ditangani serius.

Pada umumnya Perguruan Tinggi Agama Islam belum mampu menyelenggarakan layanan bimbingan dan konseling profesional yang menyentuh semua bidang (pribadi-sosial, akademik, dan karir) yang sejajar, sejalan dan sinergis dengan Bidang Intruksional Kurikuler (IK), Bidang Administrasi dan Kependidikan (AK) karena belum ada regulasi khusus yang mengatur penyelenggaraan BK di perguruan tinggi, tidak tersedianya SDM konselor profesional di PTAI, tidak tersedia unit pelaksana bimbingan dan konseling profesional di tingkat universitas. Kondisi ini mempertegas belum ditemukan pola dan pendekatan khusus untuk penanganan kasus prokrastinasi akademik mahasiswa. Mayoritas di Perguruan Tinggi Agama Islam, pelayanan masalah akademik mahasiswa ditangani oleh Dosen Pembimbing Akademik (DPA) yang lebih dominan pada layanan yang bersifat administratif, aspek pribadi dan sosial mahasiswa yang ditangani pada batas masalah umum. Mayoritas DPA belum dibekali pemahaman dan pelatihan tentang prinsip-prinsip, asas, dan jenis pendekatan layanan bimbingan dan konseling dasar yang tepat dan efektif.

Diperoleh data bahwa terdapat beberapa Perguruan Tinggi Agama Islam yang memiliki layanan karir juga memiliki divisi Bimbingan dan Konseling, namun tidak ada pelayanan dan pendekatan khusus kuratif developmental yang fokus bagi mahasiswa kasus prokrastinasi akademik. Sebagian kecil Perguruan Tinggi Agama Islam memiliki unit pelayanan bimbingan dan konseling di fakultas tertentu (fakultas keguruan dan dakwah) dan tidak ada layanan khusus yang fokus membantu mahasiswa kasus prokrastinasi akademik.

\section{KESIMPULAN DAN IMPLIKASI}

\section{Kesimpulan}

Mahasiswa kasus prokratinasi akademik di salah satu program studi lingkungan PTAI mencapai kurang lebih $17,8 \%$, jumlah yang hampir sama dengan mahasiswa kasus prokrastinasi akademik program studi di PTU. Dapat diprediksi bahwa jumlah mahasiswa kasus prokrastinasi akademik di lingkungan PTAI pada setiap fakultas dengan kisaran yang sama. Dengan demikian mahasiswa kasus prokrastinasi akademik di PTAI seluruh Indonesia mencapai taraf yang memprihatinkan. Hal ini berpengaruh nyata pada peningkatan jumlah drop out dan jumlah usia produktif yang tidak memiliki keahlian.

Bentuk perilaku prokrastinasi akademik mahasiswa ditunjukan dengan kebiasaan terlambat masuk kelas dan tidak disiplin sesuai jadwal, menunda-nunda melaksanakan tugas akademik dari dosen pengampu mata kuliah, menghindari tugas tertentu, memilih melakukan aktivitas lain dan izin belajar di kelas, jumlah kehadiran tidak memenuhi syarat minimal, nilai mata kuliah di bawah standar atau tidak lulus, IPK di bawah standar, dan terancam DO. Apabila perilaku prokrastinasi akademik mahasiswa tidak segera ditangani dan diselesaikan 
secara komprehensif dan baik, maka akan berpengaruh nyata pada perilaku buruk lainnya yang lebih serius.

Penyelenggaraan pelayanan bimbingan dan konseling di Perguruan Tinggi Agama Islam belum sesuai standar, belum berjalan secara sinergis antara Intruksional Kurikuler (IK), Administrasi Kependidikan (AK) dan Bimbingan dan Konseling (BK). Sejatinya pelayanan bimbingan dan konseling di PTAI memiliki program yang dikhususkan untuk mencapai standar kompetensi kemandirian (SKK) yang sejalan dengan Bidang Intruksional Kurikuler. Layanan bimbingan dan konseling yang diselenggarakan saat ini tidak memiliki pola dan pendekatan yang bertujuan khusus untuk membantu mahasiswa kasus prokrastinasi akademik. Wadah layanan bimbingan dan konseling yang tersedia lebih fokus pada pelayanan bidang karir (career center). Hal ini disebabkan oleh minimya dukungan dari pimpinan, tenaga profesional (konselor) tidak tersedia, dan tidak ada regulasi yang mengatur pelayanan BK komprehensif di tingkat perguruan tinggi.

\section{Implikasi}

Penting dirumuskan regulasi yang mengatur penyelenggaraan layanan BK di perguruan tinggi sehingga dapat difasilitasi tersedianya SDM profesional (konselor) di semua fakultas di Perguruan Tinggi Agama Islam (PTAI). Penting adanya upaya yang serius untuk dikaji dan ditemukan pola pelayanan bimbingan dan konseling komprehensif di Perguruan Tinggi Agama Islam. Penting untuk ditemukan pendekatan bimbingan dan konseling islami yang efektif dan efisien untuk membantu mahasiswa kasus prokrastinasi akademik.

\section{DAFTAR PUSTAKA}

Amti, E., \& Prayitno. (1999). Dasar-Dasar Bimbingan dan Konseling. Jakarta: Rineka Cipta.

Basri, A. H. (2017). Prokrastinasi Akademik Mahasiswa Ditinjau dari Religuitas. Hisbah: Jurnal Bimbingan dan Konseling Islam, 4(2), 54-77.

Djamarah. (2002). Psikologi Belajar. Jakarta: Rineka Cipta.

Fauziah, H. H. (2015). Faktor-Faktor yang Mempengaruhi Prokrastinasi Akademik pada Mahasiswa di Fakultas Psikologi UIN Sunan Gunung Djati Bandung. Psympathic: Jurnal Ilmiah Psikologi, 2(2), 123-132.

Hadi, S. (2009). Metode Research. Yogyakarta: Andi Offset.

Ilyas, M., \& Suryadi. (2015). Perilaku Prokrastinasi Akademik pada SiswaSiswi di SMA Islam Terpadu (IT) Boarding School Abu Bakar Yogyakarta. Psympathic: Jurnal Ilmiah Psikologi, 41(1), 123-132.

Khan, M. J., Arif, H., Noor, S. S., \& Muneer, S. (2014). Procrastination Among Male and Female University and College Student. FWU Journal of Social Science, 8(2), 65-70. Moleong, L. (2012). Metodologi Penelitian Kualitatif. Bandung: PT Remaja Rosda Karya.

Rahmat, A. (2015). Perilaku Prokrastinasi Akademik pada Mahasiswa Pascasarjana. Journal of Islamic Education, 1(2).

Safaati, E., Halim, M. I., \& Iliyati, Z. (2017). Peran Regulasi Diri dan Conformitas Teman Sebaya dengan Prokrastinasi Akademik pada Mahasiswa di Universitas Muria. Jurnal Insight, 7(1), 96-106.

Sujarwo, S. (2015). Hubungan Antara Regulasi Diri dengan Prokratinasi Akademik Mahasiswa Semester 4 dan Semester 6 Program Studi Bimbingan 
dan Konseling Universitas PGRI Terhadap Program Konseling di Palembang. Journal PSYCHE, 9(1), 41-48. Perguruan Tinggi. Insiht: Jurnal Vargas, M. A. (2017). Academic Bimbingan dan Konseling, 7(2), 96-106. Procrastination: The Case of Mexican Wolters, C. (2003). Understanding Researcher in Psichology. American Procrastination From a Self-Regulated Journal of Education and Learning, 2(2), $\quad$ Learning Perspektif. Journal of Education 103-120.

Psycology, 95(1).

Wahyuni, E., Nurihsan, J., \& Yusuf, S. (2018).

Kesejahteraan Mahasiswa: Implikasi 